\title{
Erdheim-Chester disease in children: clinical, radiologic, treatment characteristics of three cases
}

\author{
S Eyssette-Guerreau*1, C Job-Deslandre ${ }^{2}, \mathrm{M} \mathrm{Taghian}^{3}$, J Donadieu ${ }^{4}$, \\ P Thierry ${ }^{3}$, J Haroche ${ }^{5}$, M Taylor ${ }^{1}$, I Koné-Paut ${ }^{1}$ and TA Tran ${ }^{1}$
}

\begin{abstract}
Address: ${ }^{1}$ Department of Paediatrics, Pediatric Rheumatology, Bicêtre university hospital, Le Kremlin-Bicêtre, France, ${ }^{2}$ Department of Rheumatology, Cochin university hospital, Paris, France, ${ }^{3}$ Department of Paediatric, hospital of Vesoul, Vesoul, France, ${ }^{4}$ Department of Pediatric Onco-hematology, Trousseau university hospital, Paris, France and ${ }^{5}$ Department of Internal medicine, La Pitié-Salpêtrière university hospital, Paris, France

* Corresponding author
\end{abstract}

from $15^{\text {th }}$ Paediatric Rheumatology European Society (PreS) Congress

London, UK. 14-17 September 2008

Published: 15 September 2008

Pediatric Rheumatology 2008, 6(Suppl I):PI29 doi:I0.II86/I546-0096-6-SI-PI29

This abstract is available from: http://www.ped-rheum.com/content/6/SI/PI29

(C) 2008 Eyssette-Guerreau et al; licensee BioMed Central Ltd.

\section{Background}

Erdheim-Chester disease (ECD) is a rare non-Langerhans cell histiocytosis (NLH), characterized by bilateral metaphyseal sclerosis of long bones and visceral infiltration. The histopathological hallmark is a xanthogranulomatous infiltration of foamy CD68+ CD1a- histiocytes and Touton giant cells. Only five paediatric cases have been reported.

\section{Materials and methods}

We contacted all paediatric rheumatology and oncology centers in France. Three cases of ECD have been identified. We describe the clinical, radiological, histological characteristics and treatments.

\section{Results}

All patients were female. Mean age at onset was 5 years (patient A: 17 months, B: 7 years, C: 6 years). Mean diagnosis delay was 5 years. Initial presentation included fever, bone pain (A and $B$ ), diabetes insipidus and growth hormone deficiency $(\mathrm{C})$ with sinus infiltration. B and C developed retroperitoneal fibrosis with hydronephrosis and renal failure in C. Patient A subsequently developed exophtalmos. ECD was evoked on typical skeletal radiographies (A and $\mathrm{B}$ ), and on retroperitoneal fibrosis on RMI (B and C). ECD was confirmed histologically on biopsies (retro-orbital/sinusal infiltration and bone). All patients received corticosteroids, alone (B) or combined with chemotherapy (A and C), which was partially and temporally effective. INF $\alpha$ was then used in all patients leading to regression of lesions (B), stabilisation of disease (C) and decrease of bone pains (A).

\section{Conclusion}

Although exceptional, paediatric ECD can be evoked in case of NLH with long bone osteosclerosis and/or visceral involvement. Prognosis depends of disease localisations and their consequences. Treatment needs to be considered case by case with special interest in IFN $\alpha$. 